\title{
A questão de Taiwan: o cenário futuro mais favorável
}

\section{PAULO PEREIRA PINTO}

A eleição de Chen Shui-Bian para Presidente de Taiwan, em 18 de março de 2000, estabelece uma nova cena de partida para cenários alternativos futuros das relações entre Pequim e Taipé. Trata-se do candidato mais criticado pela República Popular da China (RPC) durante a campanha eleitoral, tendo em vista suas posições independentistas.

Antes do pleito, os mais altos dirigentes chineses desaconselharam, severamente, que os eleitores formosinos nele votassem. Após a divulgação dos resultados, o vencedor acenou amistosamente em direção ao outro lado do estreito, afirmando que não proclamaria a independência. Além disso, admitiu reiniciar negociações no âmbito do conceito de "uma China", desde que ambas as partes fossem colocadas em patamar idêntico de igualdade, isto é, cada uma considerada como "um Estado". Tal postura foi recusada pelo Presidente Jiang Zemin, cujo Governo reconhece Taiwan como uma província e a futura administração de Chen Shui-Bian como "autoridades locais".

O exercício de reflexão, a seguir, pretende sugerir, com respeito à questão, a perspectiva mais favorável a que se poderia almejar, considerando as tendências de peso identificadas poucos dias após a derrota do Kuomintang, no poder há setenta anos - 20 no continente e 50 na ilha de Formosa.

A evolução recente do assunto revela que, até o início da década de 1990, Taiwan defendia a existência de "uma China”, representada pela "República”, instalada "temporariamente" nesta ilha, com o firme propósito, ainda, de reconquistar o continente pela força. As autoridades de Taipé decidiram, então, renunciar unilateralmente à "soberania" sobre o outro lado do estreito, limitando sua jurisdição ao arquipélago formado por Taiwan e as pequenas ilhas de Penghu, Kinmen e Matsu.

É importante ressaltar, nesse ponto, a dúvida quanto a se caberia aos dirigentes locais o direito de retirar da soberania de "uma China”, parte de seu território, fosse a massa continental a que "renunciavam"- caso se queira ver o tema a partir de Taipé - ou a pequena região onde estavam instalados - na hipótese de se considerar as coisas desde Pequim. A RPC tinha, então, para o observador local, todo o direito de entender tal iniciativa como movimento em direção à independência da ilha.

De qualquer forma, diante da necessidade de estabelecer-se um canal de comunicação entre “duas entidades políticas de um mesmo país”, foi possível dar 
início, em 1993, ao diálogo através do estreito, entre duas “associações não governamentais”: a Fundação para Assuntos do Estreito, formosina, e a Associação para Relações Através do Estreito, chinesa. A moldura assim criada, segundo o que se divulga aqui, previa o estabelecimento de um longo processo de negociações, tendo em vista a reunificação, com base em que cada parte poderia manifestar seu "próprio entendimento" sobre o significado de "uma China".

Desde então, a China tem insistido que as conversações deveriam, prioritariamente, tratar de temas políticos da reunificação, enquanto Taiwan tem persistido na ênfase em questões técnicas, ligadas à pesca, repatriação e imigrantes ilegais. A principal queixa de Taipé, no entanto, é a relativa ao estrangulamento internacional da ilha, na medida em que Pequim tem conquistado, gradativamente, os poucos aliados formosinos (no momento, apenas 29 países de pouca expressão reconhecem a "República da China").

Daí o atual Presidente Lee Teng-Hui ter julgado que seria conveniente à causa formosina o pronunciamento de julho último, quando levou adiante sua proposta de divisão da nação chinesa, alegando que nela existiriam dois Estados. Não é surpresa que, em represália, o porta-voz de Pequim tivesse escalonado, também, o epíteto atribuído ao “traidor do milênio”(Lee), passando a referir-se a ele, então, como "um bebê de proveta anormal, gerado pelas forças anti-China em seus laboratórios políticos”.

Retornando-se à nova cena de partida mencionada acima, é possível verificar que, para a identificação do cenário mais favorável desde este momento, seria necessário, antes, mapear as principais tendências em gestação em quatro dimensões principais: a de segurança, a política, a econômica e a cultural.

Na dimensão de segurança, verifica-se que a RPC não cessa de reiterar a promessa de utilização da força caso Taiwan declare independência. Segundo a percepção de seus dirigentes, Chen Shui-Bian teria como seu real objetivo conforme o demonstrariam seus pronunciamentos antes das eleições - provocar tal separação e, portanto, a ameaça do emprego de meios militares seria o último obstáculo a ser oposto a seus propósitos.

Em contrapartida, os constantes acenos bélicos de Pequim levam os formosinos a buscar o fortalecimento permanente de suas defesas. Chega-se a especular em Taipé que, mesmo sem declarar independência, a ilha acabaria sendo vítima de agressão do outro lado do estreito. Exemplo disto seriam os testes de mísseis lançados pela China em 1995-96. Para as autoridades locais, portanto, trata-se de buscar apoio cada vez maior e mais garantido dos EUA, inclusive com sua inclusão no sistema de Theater Missile Defense.

Nessa perspectiva, a evolução mais favorável à China, na dimensão de segurança, seria a renúncia de Taiwan à independência, submetendo-se à soberania de Pequim sem fosse necessário o uso da força. Para os formosinos, a melhor 
tendência seria a renúncia chinesa à força, de forma a permitir que Taiwan negocie a reunificação em seus próprios termos.

Assim, os componentes desta dimensão, no cenário mais favorável da questão, seriam o "não à independência e o não à utilização da força”. O difícil, no entanto, será conseguir que ambas as partes se sentem à mesa de negociação, de forma a que, por um lado, Pequim se sinta segura de que Taipé não contemple a hipótese de independência e, por outro, Taiwan entenda ser possível negociar, em termos que lhe pareçam convenientes, a reintegração à China, sem a ameaça de que, em determinado momento, a outra parte julgue conveniente usar meios militares.

Na dimensão política, sabe-se que, para a China, a reunificação de Taiwan significará o término de um período de humilhações que lhe foram impostas desde meados do século passado, tanto pelo Ocidente quanto pelo Japão. Assim, após o retorno de Hong Kong e Macau, Formosa será a etapa final no processo de recuperação da soberania sobre todo o "Império do Centro".

Os taiwaneses, de sua parte, encontram-se expostos a sentimento nacionalista crescente. Isto porque fortalece-se a idéia de que, com as conquistas aqui obtidas, em termos de uma economia de mercado bem sucedida e de uma democracia eleitoral consolidada, a ilha conquistaria nova legitimidade para sua inserção internacional, sem precisar submeter-se aos desígnios de Pequim.

Dessa forma, para os chineses, a evolução mais favorável na dimensão política, seria a do acordo, entre as duas margens do estreito, de que existe apenas “uma China”, representada pela RPC, da qual Taiwan faz parte. Em contrapartida, para os formosinos, após a eleição de Chen Shui-Bian, a preferência passou a ser pelas negociações de "Estado a Estado”, no âmbito de "uma nação".

Os componentes da dimensão política no cenário mais favorável seriam, portanto, o retorno a "uma China, duas interpretações", sem que a discussão sobre soberania fosse condicionante para a tratativa de temas práticos e de interesse comum. Neste patamar, as dificuldades maiores dizem respeito a, por um lado, o receio de Pequim de que o espaço deixado a "interpretações” possa ser usado por Taipé para maior legitimidade internacional e, por outro, o medo formosino de ser definitivamente eliminada da vida entre nações.

Na dimensão econômica, o volume de investimentos taiwaneses na RPC (cerca de 40 bilhões de dólares) e o crescente comércio bilateral (ao redor dos 12 bilhões de dólares nos últimos doze meses) poderiam levar a crer que existe unanimidade de pontos de vista sobre a visível integração entre os dois lados do estreito e que, portanto, neste patamar, haveria invariantes e não tendências antagônicas.

Na prática, contudo, já existe competição entre as duas economias que poderia levar a hipóteses futuras alternativas. Lembra-se, a propósito, que o intercâmbio comercial entre China e Taiwan teve início na década de 1980, quando a economia da RPC começou seu processo de abertura para o exterior. Tal processo 
foi muito bem aproveitado pelos formosinos, que se encontravam em fase de reorganização de suas vantagens competitivas, em que era conveniente transferir para o continente suas indústrias menos avançadas, de utilização intensiva de mãode-obra e mesmo poluentes.

Assim, permitia-se à ilha elevar as indústrias locais a um patamar tecnológico mais avançado, enquanto suas exportações de menor valor agregado passavam a usufruir das quotas concedidas pelos países industrializados aos chineses. A República Popular, no entanto, passou também a reorganizar suas próprias vantagens competitivas, iniciando a produção de bens semelhantes aos das indústrias taiwanesas lá instaladas. Paralelamente, apesar das restrições impostas por Taipé aos limites de investimentos que poderiam ser feitos na outra margem, a economia chinesa tornou-se forte competidora da formosina, em busca do capital disponível na ilha.

Criou-se, nessa perspectiva, toda uma rede de vínculos empresariais, comerciais e financeiros, que geram tanto complementaridade, quanto conflito, a exigir a criação de instituições capazes de gerenciar tais interesses. Enquanto permanecer o impasse político sobre o reconhecimento mútuo da governabilidade de cada uma das partes, contudo, aumentará a possibilidade de que disputas no patamar econômico possam refletir-se no incremento de tensões na dimensão de segurança.

Daí, a tendência mais favorável, para um cenário futuro ideal, nas relações através do estreito, ser a adesão da China e de Taiwan à Organização Mundial do Comércio e outros órgãos reguladores da economia mundial, de forma a que normas de mercado venham a ser controladas, nesta parte do mundo, por entidade supranacional.

Finalmente, a dimensão cultural representa, na verdade, uma condicionante de qualquer cenário alternativo futuro. Isto é, nessa esfera de relacionamento, existem, entre chineses e taiwaneses, somatório de interesses compartilhados por diferentes ações das sociedades civis, ora divididas e governadas separadamente, que servirão de cimento para resgatar a identidade de uma nação. Entre esses mecanismos de cooperação, encontra-se a capacidade, demonstrada historicamente, de fazer prevalecer, diante de qualquer adversidade, os valores mais importantes de sua civilização.

Assim aconteceu, por exemplo, quando a China foi invadida, durante séculos, em diferentes momentos, por mongóis e manchus. Sempre, aqueles que demonstraram superioridade militar acabaram sendo absorvidos pela superioridade cultural chinesa. Da mesma forma, voltará a ocorrer, após o período iniciado há cinqüenta anos, durante o qual parte do território chinês tem estado inserido na fronteira ideológica de potência situada fora de região, que fornece armamento avançado para manter tal divisão. 
Conclui-se, assim, que o cenário futuro favorável para questão de Taiwan poderia ser descrito nas linhas gerais seguintes: haveria acordo quanto à renúncia taiwanesa à independência e ao término da ameaça chinesa de utilização da força para a reunificação. Prevaleceria a idéia de que existe apenas uma China, sujeita a duas interpretações, correspondente a cada margem do estreito. A discussão sobre soberania não seria pré-condição para o diálogo sobre temas práticos de interesse comum, como pesca e repatriação. RPC e Taiwan tornar-se-iam membros da OMC e sujeitariam suas disputas econômicas àquele órgão regulador mundial. A ação das sociedades civis, ora divididas e governadas separadamente, fariam prevalecer a unidade nacional, em função de valores mais altos de sua civilização.

Março de 2000 